\title{
La legalidad de la Historia: el mito fundacional de la identidad en el Chile neoliberal
}

\author{
Legality of History: the foundational myth of identity in neoliberal \\ Chile
}

\author{
Nicolás Fuster Sánchez* \\ Pedro Moscoso-Flores*
}

\begin{abstract}
Resumen
El presente texto aborda el problema de la violencia fundacional inmanente a la historia, entendida como el espacio de producción de los insumos -memoria/origen- que erigen los sentidos de pertenencia de una comunidad -identidad, cultura, etc.- En esta dirección, creemos que la emergencia de un determinado modo de comprensión de lo social -evidenciado en el gesto fundacional del decreto ley № 1 de 1973-, supondría una estrategia discursiva básica para la naturalización de una actualidad triunfal, democrática y legal; y la producción de una identidad vicaria del modelo neoliberal.
\end{abstract}

Palabras claves: Decreto Ley - Violencia - Historia - Sujeto Identidad

\begin{abstract}
This paper addresses the problem of foundational violence immanent in history, understood as the space of production of inputs -memory/origin- that awake senses of belonging in a community-identity, culture, etc-. In this direction, we believe that the emergence of a certain way of understanding the socialevidenced in the founding gesture of Law Decree No. 1 of 1973,
\end{abstract}

*Chileno, Dr. en Ciencias Sociales y de la Comunicación, académico de la Universidad de Valparaíso, contacto: nicolas.fuster@uv.cl

*Chileno, Magíster en Filosofía mención Filosofía Política y Axiología, académico de la Facultad de Ciencias Sociales de la Universidad Central de Chile, pmoscosoflores@gmail.com

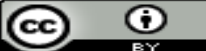


would suppose a basic discursive strategy for the naturalization of a triumphant, democratic and legal actuality; and the production of a vicarious identity proper of the neoliberal model.

\section{Key words: Law Decree - Violence -History- Subject-Identity Fuerza de ley}

El 18 de septiembre de 1973 se publica en el diario oficial el decreto ley № $1^{1}$.El llamado que se consigna en él a "restaurar la chilenidad, la justicia y la institucionalidad

\footnotetext{
'ACTA DE CONSTITUCION DE LA JUNTA DE GOBIERNO

Decreto ley N.o 1.- Santiago de Chile, a 11 de Septiembre de 1973.

El Comandante en Jefe del Ejército, General de Ejército don Augusto

Pinochet Urgarte; el Comandante en Jefe de la Armada, Almirante don

José Toribio Merino Castro; el Comandante en Jefe de la Fuerza Aérea,

General del Aire don Gustavo Leigh Guzmán y el Director General de Carabineros, General don César Mendoza Durán, reunidos en esta fecha, y

Considerando:

1.o- Que la Fuerza Pública, formada constitucionalmente por el Ejército, la Armada, la Fuerza Aérea y el Cuerpo de Carabineros, representa la organización que el Estado se ha dado para el resguardo y defensa de su integridad física y moral y de su identidad histórico cultural;
}

2.o- Que, por consiguiente, su misión suprema es la de asegurar por sobre toda otra consideración, la supervivencia de dichas realidades y

Valores, que son los superiores y permanentes de la nacionalidad

Chilena, $\mathrm{y}$

3.o- Que Chile se encuentra en un proceso de destrucción sistemática e integral de estos elementos constitutivos de su ser, por efecto de la intromisión de una ideología dogmática y excluyente, inspirada en los principios foráneos del marxismo-leninismo;

Han acordado, en cumplimiento del impostergable deber que tal misión impone a los organismos defensores del Estado, dictar el siguiente,

Decreto-ley:

1.o- Con esta fecha se constituyen en Junta de Gobierno y asumen el Mando Supremo de la Nación, con el patriótico compromiso de restaurar la chilenidad, la justicia y la institucionalidad quebrantadas, conscientes de que ésta es la única forma de ser fieles a las tradiciones nacionales, al legado de los Padres de la Patria y a la Historia de Chile, y de permitir que la evolución y el progreso del pás se encaucen vigorosamente por los caminos que la dinámica de los tiempos actuales exigen a Chile en el concierto de la comunidad internacional de que forma parte.

2.o- Designan al General de Ejército don Augusto Pinochet Ugarte como Presidente de la Junta, quien asume con esta fecha dicho cargo.

3.o- Declaran que la Junta, en el ejército de su misión, garantizará la plena eficacia de las atribuciones del Poder Judicial y respetará la Constitución y las leyes de la República, en la medida en que la actual situación del país lo permitan para el mejor cumplimiento de los postulados que ella se propone. 
quebrantadas, conscientes de que ésta es la única forma de ser fieles a las tradiciones nacionales, al legado de los Padres de la Patria y a la Historia de Chile"; nos conmina a entrar en el problema de la Historia, o más bien, a comprender su función política y estratégica: la Historia (con mayúscula) como espacio agonístico. La posibilidad de instalar la historia (una historia) como fundamento de lo político sólo se consigue en el juego de las luchas simbólicas que se dan en ese campo de batalla que es la historia, en la lucha por la representación de la historia -y de sus identidades, cultura, valores, etc.- En su Tesis VII, Walter Benjamin señala, "los que dominan a la sazón son los herederos de todos los que han vencido. Por eso, la empatía con el vencedor favorece en cada caso al dominador del momento (...) Quien quiera haya obtenido la victoria hasta el día de hoy, marcha en el cortejo triunfal que lleva a los dominadores de hoy sobre los [vencidos] que hoy yacen en el suelo. El botín, como siempre ha sido usual, es arrastrado en el cortejo. Se lo designa como el patrimonio cultural'2 (1995:52).

La apelación que se explicita en el decreto no puede entenderse sino como pieza clave de la estrategia por el dominio de la palabra que instaura, que funda, que hace historia. Es la reparación de esa continuidad quebrantada por los "principios foráneos del marxismoleninismo”. La chilenidad, la recuperación de lo auténtico, lo local, que ha sido la tradición cultural de la patria es parte del "botín" que Benjamin agudamente llama nuestro "patrimonio cultural". La violencia que se anida en esa imposición es la violencia fundadora del decreto, del bando, de la norma. El estado de derecho -su constitución, su poder constituyente, su soberanía- son el devenir de la violencia que funda el derecho y su representación de la realidad -valores, identidades, cultura, historia-.

En esta dirección, es pertinente destacar una de las cuestiones fundamentales que recorre el trabajo de Walter Benjamin -y que posee una gravedad ontológica significativa-: la pregunta por la relación entre violencia y derecho ${ }^{3}$, o más bien, la interrogación sobre la

Regístrese en la Contraloría General de la República, publíquese en el Diario Oficial e insértese en los Boletines Oficiales del Ejército, Armada, Fuerza Aérea, Carabineros e Investigaciones y en la Recopilación Oficial de dicha Contraloría.

JUNTA DE GOBIERNO DE LA REPUBLICA DE CHILE.- AUGUSTO PINOCHET UGARTE, General de Ejército, Comandante en Jefe del Ejército.- JOSE T. MERINO CASTRO, Almirante, Comandante en Jefe de la Armada.- GUSTAVO LEIGH GUZMAN, General del Aire, Comandante en Jefe de la Fuerza Aérea.CESAR MENDOZA DURAN, General, Director General de Carabineros.

Lo que se transcribe para su conocimiento.- René C. Vidal Basauri, Teniente Coronel, Jefe Depto. Asuntos Especiales, Subsecretario de Guerra subrogante.

Las cursivas son nuestras.

${ }^{2}$ Las cursivas son nuestras.

${ }^{3}$ En esta misma dirección, Jaques Derrida señala:"Hay ciertamente leyes que no se aplican, pero no hay ley sin aplicabilidad, y no hay aplicabilidad, o enforceability de la ley, sin fuerza, sea ésta directa o no, física o simbólica, exterior o interior, brutal o sutilmente discursiva -o incluso hermenéutica-, coercitiva o regulativa, 
violencia que subyace al derecho (Galende, 2009). En un texto titulado Hacia la crítica de la violencia y publicado en 1921, Benjamin señala, "Se dirá que un sistema de fines jurídicos no podrá sostenerse mientras queden fines naturales cuya obtención se pueda perseguir con violencia. Pero eso es un dogma simplemente. Contra él, quizá se pueda recurrir a la sorprendente posibilidad de que el interés del derecho en la monopolización de la violencia frente a las personas individuales no se explique mediante la intención de salvaguardar los fines jurídicos, sino, antes bien, mediante la intención de salvaguardar el derecho como tal; pues la violencia, si no se encuentra en manos del derecho, lo pone en peligro, no mediante los fines que persigue, sino ya por el hecho de su mera existencia externa al derecho" (2008:186-187).

En este sentido, el derecho y su ejercicio, según Benjamin (2008), no pueden desligarse de la violencia, ya que son recíprocos. Es decir, la violencia es el medio del derecho, y por lo tanto, es su fuerza instauradora y conservadora. Esto significaría que la violencia no es anterior al derecho, ni tampoco es sólo un efecto "residual” de su ejercicio, sino más bien "es lo que lo configura a través de un movimiento que va desde su 'instauración arbitraria', en tanto fuerza, a su mantención y conservación, en tanto poder, y viceversa” (Galende, 2009: 75). El vínculo entre derecho y violencia que opera dentro del orden jurídico dictatorial -en el decreto ley- permite sentar las bases para la imposición de nuevo orden -de una historia nueva pero que se presenta antigua, continua- y que se resolverá en la disolución del vínculo violencia/derecho a través de la invisibilización o la negación de la lucha que lo funda y lo mantiene -la apelación a los valores nacionales quebrantados, por ejemplo-. Como explica Benjamin, no se trata, entonces, de la necesidad de anular la violencia, sino de incluirla de modo particular dentro del ordenamiento jurídico.

Esta fuerza instauradora, que erige al bando o decreto, al derecho y a su estado, al Estado de Derecho siempre es violenta, ya que opera borrando la huella de su origen, es decir, anulando la legalidad de un "estado anterior" y naturalizando un origen que pasa ahora a ser la palabra iniciática del legislador. La apelación a un origen, a un momento anterior y prístino -a priori a-histórico cargado de historia- opera estratégicamente al interior del decreto como una memoria mítica que convoca a la comunidad (valores nacionales) y que conmina a una acción (rescate de la "chilenidad" ${ }^{5}$ ). En este sentido, la violencia fundacional

etc. ¿Cómo distinguir entre, de una parte, esta fuerza de la ley, esta 〈<fuerza de ley〉> como se dice tanto en francés como en inglés, creo, y de otra, la violencia que se juzga siempre injusta? ¿Qué diferencia existe entre, de una parte, la fuerza que puede ser justa, en todo caso legítima (no solamente el instrumento al servicio del derecho, sino el ejercicio y el cumplimiento mismos, la esencia del derecho) y, de otra parte, la violencia que se juzga siempre injusta? ¿Qué es una fuerza justa o una fuerza no violenta?” (Derrida, 2010: 16-17)

"Las cursivas son nuestras.

${ }^{5}$ En relación a la definición implícita que establece el decreto sobre el rescate de "la chilenidad", Patxi Lanceros señala: "todo ejercicio de definición consiste en la implementación de límites y fronteras, en el establecimiento de un territorio habitable y en la correlativa heterodesignación de un entorno inhóspito u hostil (que opera, con 
del decreto se despliega como la celebración de la memoria histórica, cuya estructura mítica posibilita la creación de un tiempo que fija su propio devenir. Es decir, se establece una repetición, una re-actualización (los valores patrios, los padres de la patria, etc.) de un tiempo -un sentido- singular en el continnum del tiempo. El objetivo de la memoria mítica -como expresión de la violencia fundacional del decreto-, es la instalación de un tiempo-proyecto originario que reclama una identidad descuidada y olvidada por "la intromisión de una ideología dogmática y excluyente”. En esta dirección, la violencia fundacional del decreto contiene, en sí misma, una suerte de fondo normativo para el sujeto; o dicho de otra forma, contiene en sus marcos de representación los modos en que el sujeto -en y de la historia- es llamado a ocupar un lugar específico dentro de su devenir, asumiendo una suerte de predestinación externa que circunscribiría los espacios posibles de ser ocupados por él y sus concomitantes modos de conducción. De esta manera, "el legado de los padres de la patria", al que apela el decreto, establece la base moral/legal -código universal- para hacer de la "Historia de Chile" el consenso de los tiempos de los pueblos de la patria. Si la historia es el lugar en el que co-existen, en una lucha constante, las diversas racionalidades que se disputan el sentido de la nación; el decreto y su violencia, la estructura mítica que le impone a la memoria -la que hoy celebramos en democracia ${ }^{6}$-, es una de las formas que adopta esta lucha por la organización del tiempo y por la defensa de su carácter lineal -de su telos-. El consenso que reclama el decreto es la imposición de "un tiempo" que oscurece la diversidad de experiencias temporales y de sentidos de lo político, es decir, anula el disenso que es el corazón de la comunidad política (Rancière, 2007).

El vínculo entre derecho y violencia fue completamente funcional al carácter productivo que instala la dictadura chilena y que tiene hoy por hoy una gran rentabilidad en su continnum: "El pasaje a la globalización que opera la Dictadura, la escena de la modernización del país en los 2000, es el documento de cultura que ha dialectizado el documento de barbarie. Y en esta borradura, el cepillo a contrapelo del Informe Rettig y del Informe Valech, no consiguen interrumpir la dialéctica progresista del país; parecen irrumpir convertidos en documentos historicistas, sumidos en la intencionalidad de una modernización general que hace bien las cosas. No insistir en la relación entre el Golpe, la

\footnotetext{
la venida de Derrida, como exterior constitutivo del interior constituyente). Dicha definición, aunque se ejerza en el ámbito del discurso -o precisamente por ello- es un ejercicio de poder, un acto político (en sentido amplio); aunque sólo sea por el hecho de que de-fine o de-limita el que puede hacerlo, el que tiene poder para ello y ocupa una determinada posición: que tiende a imponerse. Los límites y fronteras producidos por la definición suelen, además, generar aranceles y peajes” (Lanceros, 2005: 114).

${ }^{6}$ Un ejemplo paradigmático de esta celebración es el ejercicio nemotécnico que propone el Museo de la Memoria. La museologización de la historia permite el acercamiento aséptico e higiénico al trauma dictatorial. $\mathrm{Al}$ respecto, Giorgio Agamben señala: "Museo no designa aquí un lugar o un espacio físico determinado, sino la dimensión separada en la cual se trasnfiere aquello que en un momento era percibido como verdadero y decisivo, pero ya no lo es más” (Agamben, 2005: 109).
} 
tortura, la Dictadura y la actualidad triunfal, sería hacerse acólito del continuum de violencia y progreso" (Thayer, 2006: 39).

La naturalización de la fuerza que da origen a la dictadura -la apelación en el decreto a valores y tradiciones en tanto fantasmagorías de una violencia fundacional- niega todo proyecto político y social anterior -y al cuerpo social que se había constituido-, eliminando a través de la Historia y de sus concomitantes -identidades, cultura, visiones de mundo, etc.- la posibilidad de un proyecto en que la diversidad sea la regla.

En esta dirección, el llamado problema de la historia nos remite al análisis de sus rentabilidades en el campo de las luchas de poder por las escenas y representaciones de la cultura y la identidad. A continuación, se indagará en la relación entre historia, identidad, memoria y la violencia que le otorga productividad al relato histórico de Chile.

\section{La Historia}

La Historiografía chilena moderna, ya sea la liberal clásica, la conservadora revisionista o la historiografía marxista de la década del cincuenta, compartió un enfoque teórico centrado en la figura del sujeto. Es decir, participaron de aquella mirada que ve en la acción del sujeto -individual o colectivo, trabajador o patrón, proletario u oligarca- el motor principal que mueve la historia moderna de nuestro país. Mientras algunos análisis encontraban a este actor social en los próceres militares de la independencia o en los políticos oligarcas de la República, otros lo reconocían en el obrero o trabajador asalariado y en sus organizaciones sindicales. Aunque existieron giros analíticos que permitieron desplazar la mirada de un tipo de sujeto histórico a otro, la historiografía chilena siguió estacionada sobre un paradigma subjetivista incrustado en un fondo narrativo universalista, general y marcado por los metarrelatos. Siguiendo esta línea, resulta notorio el desplazamiento originado en la década del cincuenta por un tipo de historiografía ya no centrada en el dirigente político, influyente empresario o prócer militar, sino en el trabajador, en sus organizaciones y en su potencial revolucionario. De este modo, la crítica a la historiografía oficial la asume una normativa con un profundo compromiso en la reivindicación de los trabajadores y en la denuncia contra la explotación imperialista. A los ojos de Gabriel Salazar y Julio Pinto, esta nueva narrativa histórica situaba al sujeto “...dentro de la estructura socioeconómica, en torno a las relaciones sociales de producción. La inserción del sujeto en dicha estructura determinaba, a priori, sus intereses de clase, de los cuales se derivaban los objetivos y estrategias que movilizaban la acción social... La lógica estructural de este esquema no admitía cambios ni contradicciones. Para el marxismo clásico, el obrero era un "ser" destinado a hacer la revolución. Su identidad se definía en la clase obrera, homogénea y ontológicamente revolucionaria” (1999: 93-94). 
Sin embargo, con el quiebre ideológico, institucional y social causado por el Golpe de Estado de 1973, la narrativa teleológica que la historiografía marxista había levantado en torno a la figura del obrero y de los movimientos sindicales, terminó derrumbándose sobre sus categorías y supuestos. Dicho quiebre supuso, además, todo un cuestionamiento a la idea de unidad nacional que resonaba en las historiografías a partir de la segunda mitad del siglo XIX, "haciendo colapsar las narrativas trascendentales del discurso nacional como elemento inherente a la historia y al cuestionamiento de su finalidad o, más exactamente, a la del sentido que tiene el duelo de la historiografía postdictatorial en su comprensión del espacio de la sociedad política” (Naranjo, 2011: 43).

Con los años, la nueva historiografía chilena se centró en la multiplicidad del mundo popular, buscando no sólo en el obrero, sino en el indígena, en la pobladora, en el estudiante o en el campesino los distintos vectores que conformarían la identidad de nuestro pueblo. De esta manera, "el obrerismo y el clasismo cedieron paso a una historia de los grupos que podían constituirse en alternativa al autoritarismo” (Devés, 1991: 128) pinochetista de la década del setenta y del ochenta. Aunque existió un cambio en el ángulo de la mirada (ésta se volcó hacia aquellos cuerpos invisibilizados por la historiografía marxista), persistió la búsqueda de una identidad, un carácter nacional del que este nuevo sujeto popular sería su depositario. Existía el convencimiento de que, "Abordado en términos de identidad, el pueblo puede ser sujeto y no sólo mártir de la burguesía y del imperialismo de que nos hablaba la historiografía de denuncia” (Devés, 1991: 129). Para esta nueva generación de historiadores existiría, según Eduardo Devés, una suerte de conciencia de historicidad articulada en la categoría de identidad que junto a la adquisición de un determinado saber y al cuestionamiento ante la realidad, permitiría a este sujeto "ser capaz de criticar y criticarse, preguntarse por el sentido de las cosas y de la propia existencia, tomar decisiones, informarse, buscar, no dejarse llevar sin consultas alternativas y sin decidir, buscar la verdad y el error, tener afán de conocer y de actuar eficiente y correctamente” (2010: 3031).

Conciencia histórica que arrancaría de la materialidad sustantiva de su quehacer empírico (Molina, 2010). Para los nuevos historiadores sociales chilenos, la "historiografía de la identidad y del sentido podía... contribuir en este proceso de apertura hacia una mayor democracia y dignidad” (Molina, 2010). En definitiva, la historia continuó buscando una salida en la narración teleológica de un sujeto que pudiese ser abordado como agente activo en la maquinaria del progreso humano.

Esta visión de la historia, centrada en un sujeto fundacional, puede entenderse conforme a los ideales impuestos por el pensamiento ilustrado moderno. El mentado Giro Copernicano, retomado y reelaborado por el filósofo Immanuel Kant, encuentra su 
condición de posibilidad en una analítica de la finitud, entendida como momento en que el hombre, en tanto objeto privilegiado del mundo, entra, paradójicamente, en una relación de limitación consigo mismo y con el conocimiento. De este modo, la finitud se transforma ella misma -y al hombre- en el lugar del fundamento. Esta evolución hacia una racionalidad antropologizada y antropologizadora abrirá una serie de cuestiones vinculadas a las formas en que los hombres definirán los saberes, las verdades asociadas a ellos y las construcciones de sentido concomitantes. Según lo anterior, la historiografía chilena adquiere determinados modos de significación -y de interpretación- en base a su configuración desde un orden ético trascendental y como efecto de la producción de la vida como una culpa (Galende, 2009). En definitiva, la historia se legitimaría en torno a condiciones axiológico-formales -el decreto ley, por ejemplo-, entendidas desde ciertos a priori que dictaminan el sentido de las relaciones entre significantes y significados, que modelan el acceso y ejercen sus efectos sobre la construcción material de la experiencia; es decir, remite a los recursos que posee el sujeto individual y colectivo- para transformarse en un sujeto moral; o dicho de otro modo, a las modalidades de reglamentación del sujeto para la construcción de la experiencia de sí mismo.

De este modo, parafraseando a Benjamin a propósito de la historia, podríamos afirmar, a modo de una aproximación tentativa al problema planteado, la necesidad de realizar un gesto destructivo hacia la Historia moderna devenida monumento ${ }^{7}$, por cuanto supone un tiempo lineal y vacío que omite estratégicamente la posición que ocupa el sujeto que, por cierto, ésta misma produce- con las normas que lo encapsulan como sujeto posible de la historia. Es decir, escapar de las unidades y de las identidades que una cierta mirada histórica -entendida como violencia fundacional tanto del bando o del decreto ley, como también de las narrativas academicistas que se erigen desde la economía de las representaciones que circulan entre las universidades y la industria cultural- plantearía como su analítica, exponiendo la artificialidad de la esencia y de su fundamento, mostrando cómo los grandes universalismos de nuestra cultura han sido el resultado de luchas de poder, deseos de dominación y prácticas de sometimiento. Así, nos veríamos impelidos a entender al sujeto como "el nombre para algo que siempre llega tarde a la experiencia así como es experiencia el nombre para aquello que irrumpe en el páramo del ser, antes o después que existencia y existente se anuden en el lecho de la subjetividad" (Galende, 2009: 40). En este punto, podemos situarnos en las cercanías de lo que el filósofo francés Michel Foucault describe como un sujeto imbricado en un complejo proceso de construcción de una historia totalitaria, integrada y homogénea. A lo anterior, el autor contrapone como alternativa el desplazamiento de la atención hacia los saberes sometidos, o sea, "los contenidos históricos que han estado sepultados, enmascarados en el interior de coherencias funcionales o en

${ }^{7}$ En nuestro caso, podemos observar como nuestra actual democracia el Museo de la Memoria y la Constitución de 1980 se erigen como "monumentos" del continnum histórico que operan estratégicamente imbricando los "padres de la patria” (Jaime Guzmán, Salvador Allende, Pinochet, etc.). 
sistematizaciones formales... toda una serie de saberes calificados como incompetentes, o, insuficientemente elaborados" (1978: 128-129).En este sentido, Foucault busca poner en evidencia la contingencia de lo que se sostiene como universal, verdadero e indiscutible, convirtiéndose en fundamento de un programa de acciones concretas. Es decir, rompe con la historia en su sentido unitario, específicamente a partir de la fractura de la noción ontológica de origen o Unsprung planteada por Nietzsche, al sostener que la historia de una cosa no responde a un progreso hacia una meta, sino a una voluntad de poder que despliega todo acontecer. Esta voluntad de poder sería la que se oscurece en los discursos modernos sobre la verdad: se borra la huella del archivo que los hizo aparecer; operación moderna mediante la cual se universalizan y naturalizan los saberes. Sólo así, nos dirá Nietzsche, es posible pensar en la historia del sentido (Nietzsche, 2006).

De ahí la urgencia de un enfoque que vea en la historia un espacio de desarticulación axiomática. En otras palabras, de un análisis histórico que no describa las identidades nacionales o el sentido histórico de nuestro pueblo, sino que se encargue de hurgar en aquellos espacios institucionales o cotidianos en los que se constituye este sujeto, en los complejos normativos en los que se forman estas identidades, en los discursos en donde se instituyen estos sentidos, para de esta manera identificar y comprender las verdaderas fuerzas que articulan e impulsan los movimientos sociales, políticos o económicos de nuestra sociedad. Podríamos pensar, en esta línea, que el olvido de la historiografía chilena ha radicado justamente en esto: al hacer el ejercicio de universalización de las categorías -dentro de las que cabe un sujeto histórico dado por supuesto- ha eliminado aquellas historias marginales que no se hilvanan de manera coherente y continua en una lógica de secuencias y categorías de sucesión.

\section{Violencia}

¿De qué hablamos cuando nos referimos a la violencia? Como bien señala Bourdieu, "los nombres llevan acoplados adjetivos tácitos y los verbos adverbios silenciosos que tienden a consagrar o a condenar, a instituir como digno de existir y de perseverar en el ser o, por el contario, a destituir, a degradar, a desacreditar" (Bourdieu, 2002: 19). El trabajoso arte de la semántica -que ya sabemos arbitrario según la lingüística- se perfila para esta pregunta inoperante frente las aspiraciones de las ideologías. La violencia, propaganda de cientos de discursos e intereses, no escapa a la lógica, como señala Nietzsche, del "derecho del señor a dar nombres" (Nietzsche, 2006: 38). Para Deleuze (2009) los conceptos son creación, y por lo tanto un "concepto no es en absoluto algo dado... Lo que está dado, en última instancia, podría siempre llamarse flujo. Los flujos están dados, y la creación consiste en recortar, organizar, recortar flujos, de tal manera que se dibuje o se haga una creación alrededor de ciertas singularidades extraídas de ellos” (2009: 8). 
En este sentido, la violencia podría ser el argumento del orden -decreto, bando, norma, estado de derecho, etc.-, pero para orden debe aplicarse la misma regla: el concepto dependerá de una cierta operación de creación y de poder. De creación en la elección y organización de ciertas singularidades, y de poder en su posicionamiento táctico en la economía de los discursos que circulan en una sociedad.

Dicha economía dependerá de una cierta narrativa maestra (Naranjo, 2011), es decir, del discurso histórico que distribuye los sentidos que colman los distintos espacios encargados de narrar la nación, el progreso o las lógicas identitarias de los sujetos -colectivos o individuales-. Hablaremos, entonces, de una violencia ejercida en tanto violencia de la historia. Esta conceptualización se hace cargo de una violencia en cuanto condición ontológica, que remite a un tipo de racionalidad moderna-ilustrada; la racionalidad del funcionamiento de una máquina social -sistema de producción y colonización de deseo, instancia de apropiación-, al decir de Deleuze (1995). Máquina que opera en la categoría y que se torna categorizante: el sentido teleológico de la historia, del hombre como su sujeto fundacional -sujeto continuo, unitario, sintético, etc.-. Podemos, de este modo, pensar la violencia como constitutiva de dicha racionalidad. Racionalidad que establecería los modos de distribución de las cadenas de significantes específicos ligados a ciertos significados, generando la idea de un gran Orden que define a los órdenes plurales. Es en este espacio (el Orden como un gran demiurgo) en el que estos modos de hacer sentido -verdades históricas- operan como modos de adjetivación. Aquí subyace la lógica de la narrativa de la Historia, con sus hitos fundacionales -Estado, Constitución, Nación, etc.-.

Sin embargo, en un segundo momento, estas formas de sentido que se instituyen como violencia de la historia, generan un efecto residual sobre la manera en cómo se constituye lo social. En este sentido, creemos que, en el contexto del Chile moderno, este espacio se instituiría como pura amenaza. Por ende, la forma de vinculación con lo social -el modo de llenado o saturación de dicho espacio- estaría determinado por una fuerza de determinación moral ontologizada. Dicha lógica es completamente funcional a la racionalidad que constituye el discurso histórico, por lo que entre el discurso hegemónico (el Orden) y contrahegemónico (lo Otro), existiría una imbricación estratégica. La incorporación de los discursos emancipatorios a la lógica del discurso universal (Laclau, 1988) -en cuanto narrativa histórica-, no se jugaría en las particularidades discursivas que sitúan a la emancipación como contra-ideología. Es decir, las reglas de emergencia de lo social operarían a través de una determinada localización taxonómica que sitúa las relaciones dialógicas del espacio público en una constante referencia a la amenaza, en cuanto condición de su emergencia. De esto, podemos desprender que los modos en que los actores sociales se encuentran llamados a ocupar dichos espacios estarían ya condicionados a priori. Así, la historia en tanto "repetición" o sino cosmológico -como por ejemplo, la referencia reiterada a la dictadura pinochetista como marco para pensar el hoy-, no es más que la violencia ontológica 
operando como narración de lo social sobre esos lugares ya pre-establecidos y pre-definidos. Lo social, en esta lógica, siempre emergerá como alteridad nominada de antemano, permitiendo su control y potencial regulación. De este modo, esta racionalidad operaría como un espacio de sentido naturalizado, incorporado la emergencia de lo Otro para constituirse en una verdadera maquínica expansiva.

\section{Identidad}

Si consideramos que la identidad se constituye en un elemento fundante de los relatos historiográficos nacionales, será necesario entonces dilucidar los elementos subyacentes que la sostienen como categoría discursiva legitima. En otras palabras, cobra relevancia enfocar la pregunta hacia las razones de sentido que sitúan la construcción de una narrativa históricoteleológica dentro de un marco de lucha identitaria. Más aún, considerando que dicha disputa simbólica se juega en los límites formales del pensamiento, en una economía de la representación (Naranjo, 2011), promoviendo de este modo una forma particular -no única, aunque significada como tal- de escritura sustancial sobre la historia.

A propósito de la necesidad de crear una nueva conciencia de historicidad que provoque una identidad nacional -lo que podríamos nominar como la necesidad de una política de la identidad-mostrada por los nuevos archivos ${ }^{8}$ historiográficos chilenos, nos parece atingente la lectura que realiza el pensador francés Jacques Rancière (2007a) respecto a los modos de funcionamiento y regulación de los mecanismos de construcción identitaria. Esto, a propósito de una problematización que enfrenta lo político, entendido como espacio de lucha entre una policía de la identidad que busca instituir los límites de separación entre lo Mismo y lo Otro por medio de mecanismos de adjetivación discursiva, y una política, que asume un a priori de igualdad fundamental entre los hombre que posibilitaría la promoción de determinados espacios de libertad. De este modo, Rancière apunta a que el discurso moderno universalizante, propio de la policía, pondría en marcha un dispositivo orientado a la creación del sujeto/objeto que habrá de marginar, es decir, dirigido a una construcción ontológica -categorizable- de lo múltiple, anónimo y sin ley que escapa a los márgenes del consenso. Lo anterior funcionaría al modo de una compleja maquinaria de control molar, de conceptualización y agrupación de todo aquello que queda fuera de los márgenes del

${ }^{8}$ La noción de archivo es abordada, en el presente texto, desde una perspectiva que alude al sistema de condiciones históricas de posibilidad de los enunciados: "En efecto, los enunciados, considerados como acontecimientos discursivos, no son ni la mera transcripción del pensamiento en discurso ni el sólo juego de las circunstancias... Las reglas del archivo definen: los límites y las formas de la decibilidad(de qué es posible hablar, qué ha sido constituido como dominio discursivo, qué tipo de discursividad posee este dominio); los límites y las formas de la conservación (qué enunciados están destinados a ingresar en la memoria de los hombres pos la recitación, la pedagogía, la enseñanza; qué enunciados deben ser reutilizados)" (CASTRO, 2004: 22). 
discurso de la ley para, de este modo, lograr asirlo y situarlo dentro de precisos marcos. Es, en definitiva, un mecanismo doble en que el discurso universal crea su objeto, a partir de su nominación, para lograr, posteriormente, realizar sobre él la operación de exclusión: “QQuién hace esta operación? Es la ley, la instancia de lo universal que manda lo particular. Pero ella lo hace de una manera bien específica, no tanto discriminando propiedades, sino elaborando una categoría específica de lo múltiple como categoría del Otro que no puede ser acogido... Ella reúne todos los regímenes de alteridad en uno solo, poniendo, por ejemplo, el predicado 'ciudadano' en posición de término medio entre el predicado 'inmigrante' y el predicado 'delincuente”" (Rancière, 2007a: 47-48).

Comentamos esta referencia con el objeto de mostrar el funcionamiento de lo que entendemos como una racionalidad del discurso dominante ${ }^{9}$, es decir, aquello que se configura como un espacio de circulación en torno a la inclusión/exclusión de identidades y que encuentra su fuerza, a nivel discursivo, en su potencial expansivo. Por lo tanto, habría que considerar que la lucha por el reconocimiento de los nuevos actores sociales que ostentan alcanzar la legitimidad identitaria circula en torno a una identificación imposible, por cuanto acceder a ellos constituiría la disolución de su alteridad radical inasible. Sería, por decirlo de alguna forma, el costo a pagar para poder ingresar dentro de los límites de lo decible.

Las configuraciones identitarias no sólo operan a partir de la definición de saberes y categorizaciones, por parte de los discursos. Se pueden apreciar, además, respecto de las prescripciones normativas inscritas en las lógicas relacionales dentro del espacio social, es decir, como catalizadores en la emergencia de la otredad dentro de ciertos márgenes. En esto, el consenso puede ser pensado como una tecnología discursiva moderna, por cuanto supone la preexistencia de una base de legitimidad en los modos de vincularse socialmente dentro de las sociedades democráticas contemporáneas, estableciendo unos límites infranqueables que definen estructuralmente las formas posibles de interacción y/o

\footnotetext{
${ }^{9} \mathrm{~A}$ propósito de lo anterior, nos parece relevante la discusión que dirige Michel Foucault en torno las razones por las que el socialismo soviético no logró establecerse frente al liberalismo. Esto, según el autor, se habría producido en la medida que el régimen soviético no logró desarrollar una gubernamentalidad propia, cuestión por la que siempre habría estado condenada a definirse como una suerte de alter ego del liberalismo: "No hay racionalidad gubernamental del socialismo. De hecho, el socialismo -y la historia lo ha demostrado- sólo puede llevarse a la práctica si se lo conecta con diversos tipos de gubernamentalidad. Gubernamentalidad liberal, y en ese momento el socialismo y sus formas de racionalidad cumplen el papel de contrapeso, correctivo, paliativo a sus peligros internos... Me parece que si, por el contrario, tenemos una inclinación tan intensa a hacer al socialismo esa pregunta indiscreta que jamás hacemos al liberalismo: “¿eres verdadero o falso?”, es justamente porque en el primero falta una racionalidad gubernamental intrínseca y esa [ausencia de] racionalidad gubernamental, que le es esencial y, creo, hasta el momento insuperable, ese problema de racionalidad gubernamental interna, se sustituye por la relación de conformidad con su texto. Y esta relación de conformidad con un texto o una serie de textos está destinada a enmascarar una ausencia de racionalidad gubernamental” (2008: 118-119).
} 
movilización social. De ahí la importancia que ha cobrado en nuestra actual democracia neoliberal la lógica de la mesa de diálogo -o democracia de los acuerdos-, en cuanto espacio consagrado a la instalación de un consenso que opera como la borradura del conflicto político y de sus partes. La mesa de diálogo se transforma de este modo en un artefacto de respuesta a lo político, es decir, al choque entre los mecanismos de normalización y homogenización, a la emergencia del disenso y a la denuncia de una falta. Además, genera un efecto sobre la opinión pública, permitiendo a cada ciudadano un posicionamiento moral -dentro de una dualidad metafísica preestablecida- frente al conflicto, eliminando de esta forma las complejidades y aristas del mismo. Al respecto, señala Rancière“... el consenso... significa un modo de estructuración simbólica de la comunidad, que evacúa el corazón mismo de la comunidad política, es decir, el disenso. En efecto, la comunidad política, en sentido propio, es una comunidad estructuralmente dividida, no solamente dividida en grupos de interés o de opiniones, sino respecto a sí misma: un pueblo político no es nunca la misma cosa que la suma de una población. Siempre es una forma de simbolización suplementaria respecto a toda cuenta de la población. Y esta forma de simbolización es siempre una forma litigiosa” (2007b: 24-25).

En suma, podríamos pensar que la identidad -como registro de lo propio que, simultáneamente, me diferencia del otro-, posibilitaría la creación de determinados límites de lo aceptable a partir de la predefinición de condiciones de adjetivación de la alteridad. Así, estaríamos tentados a posicionar dicha estrategia de categorización como una estructura de anudamiento que operaría por medio de la definición de un marco identitario que niega la inclusión del otro indeterminado y lo sustituye por un otro excéntrico, lo que a su vez promueve una naturalización y designación de determinados criterios de realidad. No es extraño, volviendo a la lógica de las actuales movilizaciones estudiantiles, que la emergencia del estudiante movilizado genere, en un primer momento, la suspensión de los sentidos articulados en torno a él. Su figura cobra sentido en la sala de clases y se articula semánticamente con las ideas de movilidad, civismo, disciplina y aspiración. Su emergencia devenida movimiento activa mecanismos de adjetivación que lo tornan otro reconocible y, por ende, describible. Esta adjetivación responderá, en un primer momento, a una política identitaria que vincula al alumno, en su relación con el espacio público, con lo criminal: estudiante-encapuchado, estudiante-delincuente, estudiante-desorden público. Sin embargo, tecnologías como la del consenso, permitirían una progresiva normalización de este otro excéntrico: estudiante-dirigente, estudiante-demanda legítima, estudiante-igualdad social.

El problema se dirimiría, de este modo, en torno a los modos de relación entre la política y el sentido de lo propio de la comunidad (identidad)que afecta tanto al discurso hegemónico como a los discursos minoritarios: "El esquema lógico de la protesta social, en general puede resumirse así: ¿pertenecemos o no a tal categoría -ciudadanos, hombres, etc.y qué es lo que resulta de eso? La universalidad política no está en hombre o en ciudadano. 
Está en el “¿qué es lo que resulta de eso?”, en su implementación discursiva y práctica (Rancière, 2007a: 20).

En este mismo sentido, el filósofo español Jesús Hernández (2005) describe los modos en que el discurso racional moderno ha logrado establecer su hegemonía por medio de un ejercicio insidioso del poder, en que su fuerza radicaría precisamente en la capacidad de incorporar a este otro dentro de la cosmovisión dominante. Lo anterior permitiría integrar a los sujetos dentro del mundo, pero siempre bajo los parámetros del discurso que define las reglas deljuego, produciendo -o modelando- la subjetividad de los mismos.

Volviendo sobre nuestro foco problemático, a saber, el problema de la identidad y el cuestionamiento de los límites impuestos por una violencia que se ejerce en el presente desde la producción de continuidades y fijación sincrónica de los desplazamientos en las fuerzas históricas, la historiadora chilena María Angélica Illanes (2011) comenta sobre las profundas dificultades que reporta actualmente la pregunta por el quiénes somos en Chile. Frente a esto, afirma que a partir del período de independencia se habría gestado una identidad extranjera en base a marcos que buscaban responder a una negación fundamental de nuestras raíces -la tierra y nuestros ancestros indígenas-, siendo hipostasiada por una identidad ex-traída: "La independencia del siglo XIX fue el comienzo de los trámites de nuestra adopción y de la búsqueda de reconocimiento de una extraña no-madre-maquillada blanca-europeo-gringa. Marcó el proceso de construcción enajenante de nuestra "identidad adoptiva". Dicha identidad nacional, construida y monumentalizada dentro de los textos de nuestra historia, habría sido posible sólo a partir de la negación de una identidad primera, un primer cuerpo -como ella misma lo llama-, resultando en una lógica del reconocimiento unilateral a partir de una serie de discursividades europeas y norteamericanas que transformaron el problema en uno cercano al desgarramiento (Illanes, 2011).

A pesar que la visión de la historiadora insistiría en el carácter ontológico de la identidad, plasmada en su concepción de una identidad originaria, resulta interesante puntualizar que dicha identidad primera vendría a interrumpir el círculo dialéctico por cuanto no reconoce una otra identidad reflectante que aglutine y homogenice; por el contrario, contiene, en sí misma, la interrupción de la pregunta ¿quiénes somos los chilenos? De este modo, según Illanes (2011), sería posible emprender un nuevo modo de identificación enfocada en la práctica del contarse las narraciones que nos dicen desde donde venimos, basado en los modos ancestrales propios del raigambre indígena mapuche. De acuerdo a esto, creemos, sería posible emprender un ejercicio desconstructivo que tensione la identidad, como categoría de posesión y fijeza, reemplazándola por un movimiento y flujo constante de identificaciones centradas en una práctica de emplazamientos y aplazamientos, de localizaciones plurales y heterotópicas, a propósito de una noción de relato sin fondo sustancial que altera la temporalidad de la continuidad histórica. 
Desde otro registro, pero en una línea análoga, el sociólogo Aldo Mascareñoexplica, a propósito de los modos en que el marco histórico identitario ha configurado las categorías de lo decible en el Chile contemporáneo -es decir, de una grilla de inteligibilidad y de sus efectos-, cómo los grandes conceptos tales como el de cultura chilena pueden ser comprendidos como una ficción real, es decir, una ficción que posee efectos reales y materiales orientados a regular las relaciones de inclusión y exclusión entre los individuos y los sistemas a los que pertenecen. Al respecto, comenta "Los chilenos, mapuches, los trabajadores, los políticos, los movimientos sociales, las organizaciones, formulan una descripción cultural cuando identificarla de algún modo se convierte en un pilar para la fundamentación y legitimación de la acción, cuando para sus objetivos estratégicos de inclusión o exclusión, la ficción de una tradición que cuidar y de una identidad que defender se transforman en la herramienta decisiva para justificar lo que de otro modo es injustificable, porque es puro vacío lo que está en el fondo y porque para no caer eternamente en ese vacío, él se llena con una autodescripción que aporta una finalidad y un terreno en apariencia seguro sobre el cual pisar: el de la ficción cultural como ficción real... Desconfiar, en definitiva, de que exista algo denominado "cultura chilena" que sea más que una ficción con determinados fines e intereses propios, aunque en ese sentido, una ficción real” (2008: 183184).

\section{Conclusión}

Como ya comentamos, autores como Gabriel Salazar, Julio Pinto o Eduardo Devés han esbozado un intento de historia que, sin dejar de lado una cierta mirada teleológica, se ha encargado de hurgar en los relatos de los bajos fondos -no dejándose seducir por el relato de las historias oficiales-, con el fin de encontrar nuevas claves que expliquen las inflexiones sociales que el siglo XX dejó en nuestro país. Esta Nueva Historia se ha hecho vital para entender, por ejemplo, la creciente instalación en la sociedad chilena de una manera de ver lo social ${ }^{\circ}$-la circulación social, individual o grupal a través del espacio público- como

\footnotetext{
${ }^{10}$ Respecto a la operatividad variopinta e históricamente contingente que cobra la noción de lo social, el sociólogo francés Jacques Donzelot realiza un exhaustivo análisis, con fuertes componentes genealógicos, que tiene por objetivo realizar un rastreo histórico respecto de cómo esta noción se construye como una ficción destinada a hacer gobernable a la sociedad, en un intermedio entre lo civil y lo político en la Francia republicana decimonónica. Específicamente, rescatamos la alusión al surgimiento del sentido de la solidaridad, como concepto instituyente que permitió el aseguramiento de un Estado político que ponía el énfasis en la necesidad de mantener una libertad de los sujetos, al tiempo que permitía una intervención del Estado en la vida de la población. Al respecto señala: "Me gustaría demostrar cómo la respuesta a esas preguntas aparece con la noción de solidaridad, que daba un fundamento a la intervención del Estado, con la técnica del derecho social como modalidad de esa intervención, con la fórmula de la negociación como capaz de resolver en la sociedad el sistema de expectativas y temores entre los grupos y los individuos, nuevo paradigma de la vida social que reemplazaba con la permanencia de su ritual el viejo sueño del contrato inaugural. Pero, sobre todo,
} 
amenaza. Utilizando la metáfora del olvido, la Nueva Historia ha hallado una herramienta para volver a recordar aquellos aspectos reprimidos, pero importantes de nuestra historia nacional. Estos ven la historia oficial como una memoria enferma que había escondido trozos de su biografía (Devés, 1991).

En este escenario, Alfredo Jocelyn-Holt explica que este ejercicio, que consiste en olvidar la historia, se hace imprescindible para poder reconstruirla desde la desmitificación del relato oficial. Al respecto nos señala: "Olvidar no a fin de encontrar un refugio amnésico paradisíaco, sino olvidar a fin de poder volver a recordar con un poco más de lucidez, perspectiva, y quietud mental" (2004: 18). Sin embargo, nuestra sofisticada conciencia histórica -la capacidad de recordar sólo lo funcional a un relato autobiográfico coherente, como señala Jocelyn-Holt-, ha colocado trabas a este proceso de desconstrucción de nuestra historia, logrando finalmente construir relatos oficiales cuya función ha sido articular una memoria nacional sin ripios: "Precisamente porque hemos sabido, desde hace ya cierto tiempo y demasiado bien, que a la historia no se la puede borrar tan fácilmente, más aún, porque sabemos que es especialmente peligrosa -la historia no brinda un consuelo fácil, hace demasiadas preguntas comprometedoras-, precisamente por eso es que hemos hecho lo indecible, lo inaceptable para doblar la página. He ahí las distintas "versiones oficiales" que se promueven de tanto en tanto" (2004: 18).

Pensamos que existe una estrecha vinculación entre la funcionalidad de estos particulares usos de la memoria y la construcción de una identidad nacional, en tanto modo de promoción de un espacio común que remite a la conmemoración de la herencia cultural e histórica. En esta dirección, el bando o decreto como apelación al "rescate" de un origen común establece una vinculación estratégica entre memoria e identidad, lo que se plasma en un ideal de comunidad con fuertes componentes cercanos a la necesidad de promoción de un sentido de Nación sin fisuras. Esto podría entenderse como una suerte de montaje predeterminado, cuyo efecto radicaría en que los individuos -con muchas cosas en comúnentren en una relación colectiva con el olvido.De este modo, se configuraría una memoria social, que cobra institucionalidad en una memoria histórica como producto de una tensión provocada por el olvido.

De este modo, gran importancia cobra el hecho de que la historiografía nacional dé por supuesta una determinada noción de sujeto que ha de ocupar los espacios de fuerza narrados por la misma, omitiendo la relación que ocupa con las normas que lo encapsulan como sujeto posible de la historia. Si nos detenemos en esto un momento y lo situamos

me gustaría tratar de mostrar cómo, en torno a esa noción, esa técnica y a ese procedimiento se había constituido un modo específico de organización de la sociedad, lo social, en la intersección de lo civil y lo político, mediatizando esos dos registros allí donde se había creído posible su articulación inmediata” (2007: 53). 
como un artilugio propio de las determinaciones de los espacios de saber y poder, podremos ver que el problema se nos invierte. Es por esto que resulta pertinente retomar la problematización que el propio Foucault nos entrega al denunciar la necesidad de dejar de comprender al sujeto como sustancia y abordarlo como forma. Esto implica entender que ni el sujeto ni las categorías que lo constituyen y lo definen como tal son esenciales, sino que son construcciones discursivas de carácter histórico que emergen en momentos particulares y que han sido modificadas y desplazadas de acuerdo a regímenes de verdad. Así, lo que caracterizaría la construcción de la subjetividad moderna residiría en tres elementos fundamentales: por un lado, como un espacio de escisión que se reafirma en la negación de la alteridad; por otro, como una subjetividad que se encuentra normalizada en torno a objetivos de rendimiento y operatividad del sistema; y finalmente, como sometida a una verdad interior, es decir, como una subjetividad ligada a una identidad que posee un fundamento o verdad esencial (Castro, 2008).

Es en esta dirección que Foucault nos plantea "que el individuo moderno no es la base atómica de una sociedad ni una ilusión de la economía liberal, sino un artefacto efectivo con un muy largo y complejo proceso histórico” (1990: 42). En este sentido, su "hipótesis es que el individuo no es lo dado sobre lo que se ejerce y aferra el poder. El individuo, con sus características, su identidad, en su hilvanado consigo mismo, es el producto de una relación de poder que se ejerce sobre los cuerpos, las multiplicidades, los movimientos, los deseos, las fuerzas" (Foucault, 1978: 120).

Es por esto que, tal como señala el filósofo esloveno Slavoj Žižek, en Foucault se plantea una relación entre prohibición y deseo circular e inmanente: "El poder y la resistencia (el contrapoder) se presuponen y generan recíprocamente: las mismas medidas prohibitivas que clasifican y regulan los deseos ilícitos, en realidad los generan... Foucault insiste en que los mecanismos disciplinarios del poder producen el objeto mismo sobre el cual ejercen su fuerza (el sujeto no es solo lo oprimido por el poder, sino que emerge como producto de esa opresión)” (2005: 267).

Lo anterior nos retrotrae a una relectura del problema moderno concerniente a la libertad -en la que, por cierto, se anclan las construcciones teleológico-historiográficas a las que aludimos-: no se trata de un individuo sometido a poderes del Estado de los que precisará emanciparse -pensamiento propio de las teorías críticas marxistas-, sino librarse de las formas de individualidad que somos nosotros mismos a partir de este poder. En este sentido, las posiciones tradicionales e ideológicas que han centrado su argumentación en un actor/sujeto como individuo libre/alienado no han hecho más que oscurecer, en este juego de binomios que cristalizan la noción de poder, las formas sutiles en que este opera, posicionándose sobre los sujetos y cruzándolos sagitalmente en sus aspectos más íntimos.En este sentido, señala Žižek, el sujeto mismo que resiste a la disciplina y el control, el acto 
mismo de su refracción: “... en su núcleo más profundo está marcado por ellas, está formado por ellas. El ejemplo fundamental de Foucault sería el movimiento obrero del siglo XIX que apuntaba a la 'liberación del trabajo'... el trabajador que quería liberarse era un producto de la ética disciplinaria: en su intento de sustraerse a la dominación del capital, quería ser un trabajador disciplinado que trabajaba para sí mismo, que era su propio patrón (y de ese modo perdía el derecho a resistir, puesto que no podía resistirse a sí mismo...). En este nivel, el poder y la resistencia están efectivamente atrapados en un abrazos mortal recíproco: no hay poder sin resistencia (para funcionar, el poder necesita una $\mathrm{X}$ que eluda su aprehensión); no hay ninguna resistencia sin poder (el poder ha sido ya el formador del núcleo en cuyo nombre el sujeto oprimido se le resiste)” (2005: 269).

De este modo, el eje de nuestro texto parece desplazarse en relación con su pregunta inicial. Si en un primer momento señalamos lo problemático de pensar un sujeto que, por decirlo de alguna manera, se veía restringido de antemano por un régimen de verdad que decide a priori las formas de ser reconocible o no reconocible de acuerdo a un determinado fondo normativo devenido identidad, en adelante el problema que se nos impone es el de situar la existencia de dicho sujeto en unos regímenes que incorporan no sólo la visibilidad del mismo, sino sus condiciones de aparición y existencia. En síntesis, el sujeto de la historia -para poder existir como ocupando determinado lugar, explícito o implícito-, se encontraría mediado por determinados cortes normativos de flujo del deseo encargados de crearlo -en tanto distribución discursiva de lo que se puede decir sobre él- y determinar sus relaciones de sentido posible. Y lo anterior no afecta únicamente al sujeto en su construcción individual o social, sino también las determinaciones formales de las relaciones que definen los campos de legibilidad que a su vez cooperan en la construcción del sujeto en una suerte de círculo dialéctico -y que en nuestra historia se dan casi siempre estructuradas en dualidades que se juegan alrededor de lo rico/pobre, oligarquía/proletariado, etc.- Sin embargo, habría que hacer la aclaración de que dicha restricción operaría desde el sujeto mismo, siendo el fondo normativo una incrustación en su existencia, lo que hace que los límites entre el adentro y el afuera cobren un carácter al menos difuso. En relación con esto, retomamos los postulados Judith Butler cuando señala que "El argumento de Foucault afirma no sólo que siempre hay relación con esas normas, sino que cualquier relación con el régimen de verdad será a la vez una relación conmigo misma. Poner en cuestión un régimen de verdad, cuando este gobierna la subjetivación, es poner en cuestión mi propia verdad y, en sustancia, cuestionar mi aptitud de decir la verdad sobre mí, de dar cuenta de mi persona” (2009: 38).

Dicha posición, llamada a cuestionar el estatus ontológico del sujeto, supone que este, en el cuestionamiento de su realidad histórico-social, se pone a sí mismo en entredicho.A su vez, supondría someter a examen las normas de reconocimiento que operan sobre la base de lo que el sujeto puede llegar a ser, es decir, bajo qué marco es ese sujeto -que yo soy- reconocible. Y esto, a su vez, nos obliga a considerar el lugar que el otro 
ocupa en relación con la propia identidad. En esta línea, y a propósito de la determinación ética que se juega en esta relación, "el otro sólo se me aparece, sólo funciona como otro para mí, si existe un marco dentro del cual puedo verlo y aprehenderlo en su separatividad y exterioridad... las normas actúan no sólo para dirigir mi conducta, sino para condicionar la posible aparición en un encuentro entre el otro y yo" (Butler, 2009, p.41). Es por esto que nos atrevemos a afirmar que las relaciones diádicas, descritas en las historiografías nacionales, contienen en sí mismas las reglas de su propia enunciación -y del acontecer del sujeto-, haciendo del lugar de encuentro uno definido a priori.

Recibido: 17 agosto 2014

Aceptado: 2 marzo 2015

\section{Bibliografía}

Agamben, Giorgio. Profanaciones. Buenos Aires: Adriana Hidalgo Editora, 2005.

Benjamin, Walter. La dialéctica en suspensión. Fragmentos sobre la historia. Santiago de Chile: Editorial Arcis-Lom, 1995.

Editores, 2010.

"Hacia la crítica de la violencia”. Obras, Libro II / Vol. 1. Madrid: Abada

Bourdieu, Pierre. Lección sobre la lección. Barcelona: Editorial Anagrama, 2002.

Butler, Judith.Dar cuenta de sí mismo. Violencia Ética y Responsabilidad. Buenos Aires: Amorrortu Editores, 2009.

Castro, Edgardo. El Vocabulario de Michel Foucault. Un recorrido alfabético por sus temas, conceptos y autores. Buenos Aires: Prometeo Libros, 2004.

Castro, Rodrigo. Foucault y el cuidado de la libertad. Ética para un rostro de arena. Santiago de Chile: LOM Editores, 2008.

Deleuze, Gilles. Exasperación de la Filosofía. Buenos Aires: Editorial Cactus, 2009.

Ibérica, 1995.

El Antiedipo. Capitalismo y Esquizofrenia. Madrid: Editorial Paidós

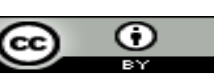


Derrida, Jacques. Fuerza de ley. El <<fundamento místico de la autoridad $\gg$. Madrid: Editorial Tecnos, 2010.

Devés, Eduardo. "La Cultura Obrera Ilustrada chilena y algunas ideas en torno al sentido de nuestro quehacer historiográfico". Mapocho. Revista de Humanidades y Ciencias Sociales, Número 30, 1991, 127-136.

Los que van a morir te saludan. Historia de una masacre: Escuela de Santa María de Iquique, 1907.Santiago de Chile: LOM Ediciones, 1989.

Donzelot, Jacques. La Policía de las Familias. Madrid: Editorial Pre-Textos, 2007.

Foucault, Michel. Microfísica del Poder. Barcelona: Editorial Pre-Textos, 1978

Tecnologías del Yo (y otros textos afines).Barcelona: Editorial Pre-Textos, 1990.

El Nacimiento de la Biopolítica. Curso en el Collège de France (19781979).Buenos Aires: Siglo XXI Editores, 2008.

Galende, Federico. Walter Benjamin y la destrucción. Santiago de Chile: Ediciones Metales Pesados, 2009.

Hernández, José. “El poder sobre la vida. Formas Biopolíticas de Racionalidad”. La administración de la vida. Estudios Biopolíticos. Barcelona: Editorial Anthropos, 2005.

Illanes, María Angélica. Chile Des-Centrado. Santiago de Chile: LOM Editores,2004.

"Por la... Madre". Conferencia realizada a propósito del Congreso

Internacional Encuentro Bicentenario: pensar Iberoamérica, memoria, historia y nuevas tramas regionales, realizado en la Universidad de Valladolid. 2011

Jocelyn-Holt, Alfredo. Historia General de Chile. El retorno de los dioses. Santiago de Chile: Editorial Sudamericana, 2004.

Laclau, Ernesto.Tesis acerca de la forma hegemónica de la política. Hegemonía y alternativas políticas en América Latina. Buenos Aires: Siglo XXI Editores, 1988. 
Lanceros, Patxi. Política mente. De la revolución a la globalización. Barcelona: Editorial Anthropos,2005.

Mascareño, Aldo. "La cultura chilena como ficción real". El Chile del Bicentenario. Santiago de Chile: Ediciones Universidad Diego Portales, 2008.

Molina, Carlos. Institucionalidad sanitaria chilena. 1889-1989.Santiago de Chile: LOM Ediciones,2010.

Naranjo, Rodrigo. Para desarmar la narrativa maestra. Un ensayo sobre la Guerra del Pacífico. Santiago de Chile: Editorial QILLQA. Serie IIAM, 2011.

Nietzsche, Friedrich. La Genealogía de la moral. Madrid: Alianza Editorial, 2006.

Pinto, Julio, Salazar, Gabriel. Historia Contemporánea de Chile II. Actores, identidad y movimiento. LOM Ediciones, Santiago de Chile.1999

Rancière, Jacques. Política, policía, democracia. Santiago de Chile: LOM Ediciones, 2007a.

El viraje ético de la estética y la política. Santiago de Chile: Editorial Palinodia, 2007b.

Thayer, Willy. El fragmento repetido. Escritos en estado de excepción. Santiago de Chile: Ediciones Metales Pesados, 2006.

Žižek, Slavoj. Ideología. Un mapa de la cuestión. Buenos Aires: Fondo de Cultura Económica,2003.

El espinoso sujeto. El centro ausente de la ontología política. Buenos Aires: Fondo de Cultura Económica, 2005.

\section{Documentos}

Decreto Ley № 1, 1973. Junta de Gobierno de la República de Chile; Ministerio de Defensa Nacional; Subsecretaría de Guerra. http://www.leychile.cl/N?i=237897\&f=1973-09$18 \& \mathrm{p}=$ 